present during hospitalisation. Twenty five questionnaires have been collected (response rate 53\%). Among patients there were 18 infants and toddlers, 3 children and 4 adolescents. Mean length of stay in the PICU was 11 days, $60 \%$ of admissions were unplanned. Questionnaires were completed mainly by mothers (84\%). Not satisfactory opinions have been given manly for understandable information on examinations and tests (12\%) and on possibility to stay close to the child during intensive procedures (16\%). All of parents declared that the team worked efficiently and the team showed respect for the patients but only $72 \%$ of parents responded that during stay in the PICU the staff regularly asked for parent's experiences.

Conclusions The EMPATHIC-30 empowers parents to provide feedback on their experiences in paediatric intensive care and may facilitate health care professionals to improve quality of care. Following a single centre experience the EMPATHIC 30 Poland study should be continued as a national project.

\section{PO-0275 ASSESSMENT AND COMPARISON OF A LAB-SCORE AND A CLINICAL PREDICTION MODEL FOR DETECTING SERIOUS BACTERIAL INFECTIONS IN FEBRILE YOUNG CHILDREN}

${ }^{1} \mathrm{D}$ Moldovan, ${ }^{2} \mathrm{D}$ Baghiu, ${ }^{1} \mathrm{C}$ Boeriu, ${ }^{1} \mathrm{~A}$ Balas, ${ }^{1} \mathrm{~A}$ Kovari. ${ }^{1}$ Emergency Department, Tirgu Mures Emergency Clinical County Hospital, Tirgu Mures, Romania; ${ }^{2}$ Paediatric Unit, Tirgu Mures Emergency Clinical County Hospital, Tirgu Mures, Romania

10.1136/archdischild-2014-307384.929

Background and aims C-reactive protein and Procalcitonin have been lately the most researched biomarkers in identifying serious bacterial infections (SBI) in febrile children. The Lab-score (2008) includes CRP, PCT and urinalysis for detecting SBI and the Clinical Prediction Model (CPM) (2013) combines clinical variables with CRP value for detecting pneumonia and other SBI separately. We aimed to assess and compare the value of the Lab-score and the CPM in identifying febrile children at risk for $\mathrm{SBI}$ in the Emergency Department (ED).

Method This survey is part of a prospective observational study aimed to identify children with fever without source at risk for SBI. Patients were recruited from Tirgu Mures Emergency Clinical County Hospital, Romania. SBI diagnosis was based on urine, blood and CSF cultures and chest radiographs. For children included, aged 1 to 36 months, the Lab-score and the CPM were calculated. Positive and negative likelihood ratios and post test probabilities were calculated for each test.

Results From 134 children, SBI was diagnosed in 31 (23.13\%): 11 pneumonia and 20 other SBI, mostly urinary tract infections. Positive and negative likelihood ratios for Lab-score $(\geq 3)$, CPM-Pneumonia $(\geq 10 \%)$ and CPM-Other SBI $(\geq 10 \%)$ were $7,25 / 0,25,22 / 0,65$ and $5,23 / 0,50$ and the post test probabilities were $69 \%, 66 \%$ and $48 \%$ for the same cut-off values.

Conclusions Both the Lab-score and CPM-Pneumonia are valuable tools in detecting SBI in febrile young children. CPM-Other SBI showed less performance than Lab-score and CPM-Pneumonia, possibly due to the lack of urinalysis value in CPM-Other SBI, which are mostly UTI.

\section{PO-0276 FEVERISH CHILDREN IN A DGH IN NORTHERN IRELAND -WHAT ARE WE DOING?}

S Mullen, D McAleese. Emergency Department, Antrim Area Hosptial, Antrim, UK

10.1136/archdischild-2014-307384.930
Aims We undertook this audit to review the management of feverish children in our emergency departments (ED) compared to The College of Emergency Medicine (CEM) standards.

Methods The data was collected using a tool designed by CEM. Entry criteria: under 5 years old and temp $>38^{\circ} \mathrm{C}$ on arrival.

Results Total number of patients was 50 . The assessed risk profile for this population (using NICE guidelines) were 24 low risk, 14 intermediate risk, 11 high risk and 1 we were unable to risk stratify from the clinical notes. Nine children were prescribed antibiotics (5 low risk, 2 intermediate and 2 high risk).

Of the 11 patients who were high risk, 7 had a clear source of infection. Of the 4 who had no source identified, one had bloods and urine performed in ED but these were not recorded in the notes. 2 had bloods performed on the paediatric ward.

For the 14 patients in the intermediate risk, 8 had a source of infection, 5 had no obvious source identified and one was not clearly documented. No patients without a source were presecribed antibiotics. No documentation was recorded about discharge advice.

18 patients $(36 \%)$ did not have a blood pressure (BP) or a capillary refill time (CRT) documented in the notes and 10 patients $(20 \%)$ did not have their GCS or APVU recorded.

Conclusions There are areas that require review. Improvements must be made to ensure a full set of observations are recorded, emphasising the importance of BP/CRT as well as GCS/AVPU.

\section{PO-0277 REVIEW OF THE MANAGEMENT AND OUTCOME FOR PATIENTS TREATED FOR WHEEZE IN A TERTIARY PAEDIATRIC EMERGENCY DEPARTMENT (PED)}

S Mullen, E Dalzell. Paediatric Emergency Department, Royal Belfast Hospital for Sick Children, Belfast, UK

\subsection{6/archdischild-2014-307384.931}

Background and aims To review the management of patients who were treated for wheeze in the PED and compare them to those in the British Thoracic Society (BTS) Guidelines.

Methods Reviewed PED flimsy of those patients over 2 who were treated for wheeze in PED in March.

Results Number of patients 46.

93\% received bronchodilators while 7\% were given Prednisolone only. $65 \%$ were given maximum nebulised bronchodilator therapy ( $\mathrm{x} 3$ sets). $89 \%$ received steroids and 2\% received IV medication. $41 \%$ received antibiotics in ED and $50 \%$ had a chest $\mathrm{x}$-ray performed.

Of those discharged $(n=32), 75 \%$ were discharged within 4 h. $31 \%$ patients were discharged within $1 \mathrm{~h}$ of last bronchodilator and a further $41 \%$ within $2 \mathrm{~h}$.

Of those treated with maximum nebulised bronchodilators (n $=30$ ), $43 \%$ were admitted, $23 \%$ discharged within $1 \mathrm{~h}$ post last bronchodilator and a further $27 \%$ within $2 \mathrm{~h}$.

$8 \%$ re-attended within $48 \mathrm{~h}-4 \%$ due to elevated temperature, $2 \%$ were uncertain with inhaler technique and $2 \%$ due to increase in symptoms.

No patient had documented evidence of written asthma management plan given or to attend primary care for review within next 48 hrs.

Conclusions The low re-attendance rate is supportive that those attending received good clinical care and in a timely manner, with $75 \%$ of patients being discharged within the $4 \mathrm{~h}$ target. However, education is required to ensure patients stay $3-4 \mathrm{~h}$ post last bronchodilator and the need for documented discharge 
advice. Education is also required on the use of chest $\mathrm{x}$-rays and antibiotics.

\section{PO-0278 MANAGEMENT OF PAIN IN ACUTE PRESENTATIONS TO A TERTIARY PAEDIATRIC EMERGENCY DEPARTMENT (PED)}

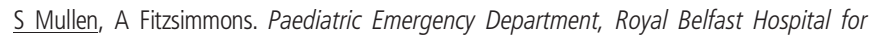
Sick Children, Belfast, UK

10.1136/archdischild-2014-307384.932

Background and aims To review pain assessment and management in our PED.

Methods We reviewed the filmsy for patients who were coded as soft tissue injury, fracture or burn over a 6 day period in June 2013 and compared this to standards set by College of Emergency Medicine (CEM) in the UK.

Results Number of patients $=67$

$98 \%$ did not have a pain score recorded from triage. No recorded pain score from any medical personnel.

$49 \%$ received analgesia with $82 \%$ receiving paracetamol alone and $15 \%$ receiving oramorph. Of those receiving analgesia, $70 \%$ did so within 20 min of arrival and $85 \%$ within first hour.

There was no documented re-assessment of pain scores although $6 \%$ of patients did receive further analgesia.

Conclusion The results hi-lighted a need for re-education of nursing and medical staff on the benefits of pain scores. Coupled with this re-education there will be a review of the current PED filmsy with a greater emphasis on pain scales, pain scores and prompts to re-score.

There are good points to be taken from the data. $70 \%$ of patients received analgesia within $20 \mathrm{~min}$ of presentation compared to $43 \%$ from the CEM annual audit in 2012. $6 \%$ of patients also received further analgesia to manage their pain. This may support the theory that although pain assessment is occurring it is not being documented.

\section{P0-0279 SKIN CONDUCTANCE CHANGES DIFFER BETWEEN PAINFUL STIMULI AND GENERAL HYPOXIA DIFFERENT FROM PERIPHERAL OXYGEN SATURATION}

${ }^{1} \mathrm{~B}$ Nakstad, ${ }^{1} \mathrm{~T}$ Nordheim, ${ }^{2} \mathrm{H}$ Hovde, ${ }^{2} \mathrm{AL}$ Solevåg, ${ }^{2} \mathrm{M}$ Thorud, ${ }^{3} \mathrm{H}$ Storm. ${ }^{1}$ Pediatric and Adolescent Medicine, University of Oslo and Akershus University Hospital, Lorenskog, Norway; ${ }^{2}$ Pediatric and Adolescent Medicine, Akershus University Hospital, Lorenskog, Norway; ${ }^{3}$ University of Oslo, Institute of Clinical Medicine, Oslo, Norway

\subsection{6/archdischild-2014-307384.933}

Background and aims Peripheral oxygen saturation $\left(\mathrm{SpO}_{2}\right)$ decreases during general hypoxia and painful events in preterm infants. Skin conductance responses per sec $(\mathrm{SCR} / \mathrm{sec})$ increase during painful procedures. The purpose of this observational study was to examine if $\mathrm{SCR} / \mathrm{sec}$ can help to diagnose if $\mathrm{SpO}_{2}$ is due to general hypoxia or painful events.

\begin{tabular}{lllll}
\multicolumn{5}{l}{ Abstract PO-0279 Table 1} \\
& $\mathrm{SpO}_{2}$ & SCR/sec & HR & RR \\
\hline No-event & $95(3)$ & $0,07(0,10)$ & $163(10)$ & $68(28)$ \\
Painful-event & $88(8)$ & $0,27(0,21)$ & $166(20)$ & $57(24)$ \\
Hypoxic-event & $69(4)$ & $0,03(0,03)$ & $153(25)$ & $61(21)$ \\
P-value & 0.002 & 0.011 & NS & NS \\
\hline
\end{tabular}

Methods Ten infants, diagnosed as ventilator unstable with birth weight $1248( \pm 710)$ grams, gestational age $30( \pm 5)$ weeks and at postnatal day $3( \pm 1)$ were observed for $1 \mathrm{~h}$ when venous blood sampling was performed. $\mathrm{SpO}_{2}, \mathrm{SCR} / \mathrm{sec}$, heart rate (HR), and respiratory rate (RR) were recorded each 2 nd minute and during the painful and hypoxic events (defined as $\mathrm{SpO}_{2}$ lower than $80 \%$ ). The variables were studied during the painful and hypoxic events as well as in situations without events. Non-parametric tests for within individual variables (Friedman's Anova) were used.

Results There were statistical differences for physiological measures during the no- painful- and hypoxic events; mean (SD):

Conclusion SCR/sec does not increase during $\mathrm{SpO}_{2}$ and may be used to differ between pain and general hypoxia in preterm infants.

\section{PO-0280 WITHDRAWN}

\section{PO-0281 ETHICAL AND CLINICAL IMPLICATIONS RELATED TO EMERGENCE PHENOMENA IN PAEDIATRIC KETAMINE SEDATION}

${ }^{1} \mathrm{M}$ Neufeld, ${ }^{1} \mathrm{~T}$ Water, ${ }^{2} \mathrm{~B}$ Carter. ${ }^{1}$ School of Nursing/Centre for Child Health Research, AUT University, Auckland, New Zealand; '2School of Health, University of Central Lancashire, Preston, UK

\subsection{6/archdischild-2014-307384.934}

Background and aims Ketamine is an efficient, economical dissociative sedative used during painful procedures as an alternative to general anaesthesia. Its physiological risk profile has been thoroughly researched; however, less well understood are the psychological events ("emergence phenomena") associated with its use. In adult practice, ketamine use is declining given the traumatic effects of emergence phenomena on patients, family, and staff. In paediatric practice, however, ketamine use is increasing despite a limited understanding of the occurrence of paediatric emergence phenomena and it's associated potential for non-physiological harm. This study analyses the ethical implications of paediatric ketamine sedation by exploring healthcare practitioners' (HCPs') accounts of paediatric emergence phenomena.

Methods HCPs (doctors, nurses, paramedics, and a play specialist) were interviewed about their experiences with emergence phenomena during paediatric ketamine sedation. Interviews were then analysed using a descriptive exploratory approach underpinned by hermeneutic narrative methods to identify common themes.

Results A focus on physiological risk has resulted in a trial-anderror approach to paediatric ketamine sedation practice. Understandings of non-physiological or psychological risk and the potential negative longitudinal outcomes in paediatric populations remain vague. "Dream seeding" (guided imagery) is widely yet inconsistently used as an anxiolytic for reducing negative psychotropic events, despite only anecdotal evidence of its effectiveness.

Conclusions Although ketamine sedation can help protect children from the pain of treatment and HCPs from emotional distress of delivering that treatment, there is potential for nonphysiological harm. The practice of dream seeding should be investigated as a tool to mitigate adverse psychotropic events. 